\title{
26481 - CARDIOPROTECTIVE EFFECT OF INSULIN AND MAINTENANCE OF NORMOGLYCEMIA
}

\section{George Carvalho MD, Ann Moore, MD; Turki Al-Backer, MD; Kevin Lachapelle, Thomas Schricker, MD PhD; Royal Victoria Hospital, Montreal, QUEBEC, Canada}

INTRODUCTION: In experimental models of cardiopulmonary bypass followed by reperfusion administration of glucose-insulin-potassium (GIK) solutions reduces myocardial necrosis and improves functional recovery.(1) In clinical practice, the heterogeneity of GIK dosing, timing, and route of administration and the concomitant hyperglycemia that almost always occurs with conventional GIK regimens, have demonstrated conflicting results.(2) Using a hyperinsulinemic euglycemic clamp $(5 \mathrm{mU} / \mathrm{Kg} / \mathrm{min})$ we were able to deliver high dose insulin to safely and predictably maintain normoglycemia in patients undergoing open-heart surgery.(3) We now hypothesize that high dose insulin together with the maintenance of normoglycemia is cardioprotective in patients undergoing coronary artery bypass grafting (CABG). METHODS: After ethics committee approval, consenting patients scheduled for elective $\mathrm{CABG}$ surgery were randomly assigned to insulin glucose treatment or standard therapy (insulin sliding scale starting at blood glucose (BG) concentrations $>10 \mathrm{mM}$, no glucose infusion). In the treatment group the infusion of insulin at $5 \mathrm{mU} / \mathrm{Kg} / \mathrm{min}$ together with dextrose $20 \%$ at a rate adjusted to maintain a BG of 4-6 mM commenced after baseline hemodynamic values ie heart rate, arterial and pulmonary pressures, central venous pressure, pulmonary occlusion pressure and cardiac index were collected. Patients were operated by the same surgeon and received standardized total intravenous anesthesia (sufentanil, midazolam) administered by the same anesthesiologist. Perfusion during cardiopulmonary bypass (CPB) was standardized as per current practice at our institution. Following CPB, inotropic support, use of vasopressors, volume and blood replacement therapy was standardized to achieve pre-defined goals. Troponin I (cTnI) was measured preoperatively and postoperatively at $0,4,8,16$, and 24 hours. Based on the results of previous studies a $20 \%$ lower cTnI level in subjects receiving insulin and glucose therapy when compared to the standard group is expected. To detect this difference with a type I error of 5\% and a power of at least $80 \% 30$ patients in each group are required. RESULTS: We present preliminary results in 30 patients. There are 14 patients in the therapy versus 16 in the standard group. Patient characteristics and surgical details are similar in both groups. Hemodynamic parameters and inotropic support are comparable between groups. Blood glucose was maintained between 4 and $6 \mathrm{mM}$ in all patients in the treatment group. The blood glucose in the standard group at skin closure was $8.4 \pm 1.7$ $\mathrm{mM}$.

DISCUSSION: Preliminary results indicate that high dose insulin therapy with the maintenance of normoglycemia is associated with lower troponin levels compared with standard care after CABG surgery suggesting a myocardial protective effect. REFERENCES:

1. Am J Physiol Heart Circ Physiol 278:H595-603, 2000.

2. Ann Thorac Surg 78:1650-8, 2004.

3. Anesth Analg 99:319-24, 2004. 
Table 1: Post-operative circulating cTnl levels

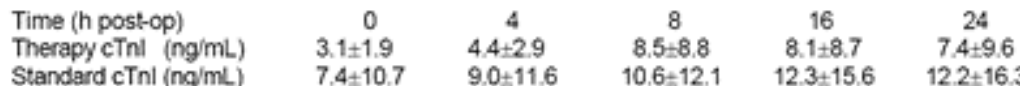

